\title{
Utilization of 2-aminoethylarsonic acid in Pseudomonas aeruginosa
}

\author{
Anne-Marie Lacoste, ${ }^{1 *}$ Catherine Dumora, ${ }^{1}$ Bassam R. S. Ali, ${ }^{2}$ Eugene NeuziL ${ }^{1}$ and \\ HENRY B. F. DIXON ${ }^{2}$ \\ ${ }^{1}$ Département de Biochimie et de Biologie moléculaire, Université de Bordeaux II, 146 rue Léo-Saignat, \\ 33076 Bordeaux Cedex, France \\ ${ }^{2}$ Department of Biochemistry, University of Cambridge, Tennis Court Road, Cambridge CB2 1QW, UK
}

(Received 17 February 1992; accepted 26 February 1992)

\begin{abstract}
This paper describes the metabolism, transport and growth inhibition effects of 2-aminoethylarsonic acid (AEA) and 3-aminopropylarsonic acid (APrA). The former compound supported growth of Pseudomonas aeruginosa, as sole nitrogen source. The two arsonates inhibited the growth of this bacterium when 2-aminoethylphosphonic acid (AEP) but not alanine or $\mathrm{NH}_{4} \mathrm{Cl}$, was supplied as the only other nitrogen source. The analogy between AEA and the natural compound AEP led us to examine the in vitro and in vivo interaction of AEA with the enzymes of AEP metabolism. The uptake system for AEP $\left(K_{\mathrm{m}} 6 \mu \mathrm{M}\right)$ was found to be competitively inhibited by AEA and APrA $\left(K_{\mathrm{i}}\right.$ $18 \mu \mathrm{M}$ for each). AEP-aminotransferase was found to act on AEA with a $K_{\mathrm{m}}$ of $4 \mathrm{mM}$ (3.85 mM for AEP). Alanine and 2-arsonoacetaldehyde were generated concomitantly, in a stoichiometric reaction. In vivo, AEA was catabolized by the AEP-aminotransferase since it was able to first induce this enzyme, then to be an efficient substrate. The lower growth observed may have been due to the slowness with which the permease and the aminotransferase were induced, and hence to a poor supply of alanine by transamination.
\end{abstract}

\section{Introduction}

The recently synthesized compound 2-aminoethylarsonic acid $\left(\mathrm{NH}_{2}-\mathrm{CH}_{2}-\mathrm{CH}_{2}-\mathrm{AsO}_{3} \mathrm{H}_{2} ; \mathrm{AEA}\right)(\mathrm{Geoghegan}$ \& Dixon, 1989) is an analogue of the naturally occurring 2-aminoethylphosphonic acid $\left(\mathrm{NH}_{2}-\mathrm{CH}_{2}-\mathrm{CH}_{2}-\mathrm{PO}_{3} \mathrm{H}_{2}\right.$; AEP). This compound is found in several aquatic animals and in some protozoa, either free or incorporated into lipids or glycoproteins (Neuzil \& Cassaigne, 1980).

The degradation pathway of AEP in Pseudomonas aeruginosa, which can utilize this aminophosphonate as a phosphorus, nitrogen or carbon source is well-known; a two-step pathway is involved. A specific 2-aminoethylphosphonate: pyruvate aminotransferase (EC 2.6.1.37) first catalyses the formation of alanine and phosphonoacetaldehyde (Dumora et al., 1983); the C-P bond of phosphonoacetaldehyde is then split into $P_{i}$ and acetaldehyde by a phosphonoacetaldehyde hydrolase (EC 3.11.1.1) (phosphonatase) (Dumora et al., 1989).

\footnotetext{
Abbreviations: AEA, 2-aminoethylarsonic acid; APrA, 3-aminopropylarsonic acid; AEP, 2-aminoethylphosphonic acid; APrP, 3aminopropylphosphonic acid.

*Author for correspondence. Tel. 575713 74; fax 56990380 .
}

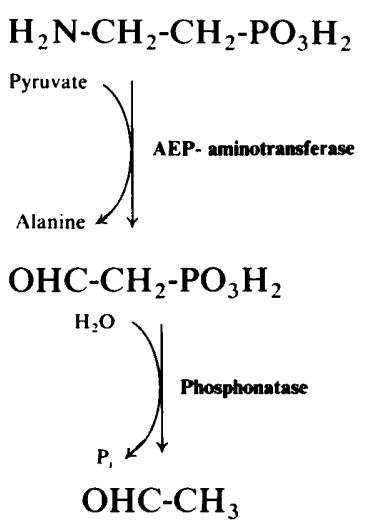

This led us to suppose that AEA might be a substrate for AEP-aminotransferase and that arsonoacetaldehyde, the product of its transamination, could act as a substrate or as an inhibitor of the phosphonatase. In this paper, we investigate the interaction of AEA with the proteins responsible for the metabolism of AEP in P. aeruginosa: the transport system, aminotransferase and phosphonatase. We also show that $P$. aeruginosa can grow in the presence of AEA as sole nitrogen source. We have therefore examined whether the in vivo degradative pathway of AEA conforms to the assays carried out in vitro, and the extent to which 3-aminopropylarsonic acid 
(APrA), the next higher homologue of AEA, can substitute for it.

\section{Methods}

Bacterial strain. Pseudomonas aeruginosa A237, obtained from the Institut Pasteur, Paris, was routinely maintained on nutrient agar at $15-18{ }^{\circ} \mathrm{C}$.

\section{Arsonic and phosphonic compounds}

2-Aminoethylarsonic acid. This was prepared from 2-chloroethylarsonic acid by the method of Geoghegan \& Dixon (1989).

3-Aminopropylarsonic acid. This was synthesized by the method of Gough \& King (1928); dichloro(3-chloropropyl)arsine was obtained by treating 3-chloropropan-1-ol successively with alkaline arsenite, $\mathrm{SO}_{2}$ (with a catalytic amount of iodine) and thionyl chloride. The arsine was oxidized to 3-chloropropylarsonic acid with hydrogen peroxide rather than with chlorine. The arsonic acid was treated with 2-aminoethanol and the resulting compound cleaved with periodate, following the procedure of Geoghegan \& Dixon (1989) for 2-aminoethylarsonic acid. On paper electrophoresis at $\mathrm{pH} 3.5$, APrA migrated towards the negative electrode as did AEA; their mobilities were, respectively, $0 \cdot 7$ and 0.35 that of arsenate, which migrated in the opposite direction. Paper electrophoresis was performed with white spirit as coolant, with the buffers of Ambler (1963). Arsonates were detected as described for phosphonates by Dixon \& Sparkes (1974), by staining with $\mathrm{FeCl}_{3}$ and sulphosalicylic acid (Wade \& Morgan, 1953).

2,3-Dihydroxypropylarsonic acid. Our method of making this acid proved to be almost the same as that of Tsivgoulis et al. (1991), which was published while our work was in progress. We prepared only the dilithium salt, however, and this avoided the difficulty of isolating the free acid. Arsenic(III) oxide $(20 \mathrm{~g}, 0.2 \mathrm{~mol})$ and $\mathrm{NaOH}(32 \mathrm{~g}, 0.8 \mathrm{~mol})$ were dissolved in water $(80 \mathrm{ml})$; 3-chloropropane-1,2-diol $(24 \mathrm{~g}$, $0.22 \mathrm{~mol}$ ) was added dropwise with stirring at about $40-50{ }^{\circ} \mathrm{C}$. The solution was then heated with stirring to $50-60^{\circ} \mathrm{C}$ for $2 \mathrm{~h}$. Electrophoresis showed that most of the arsenite had reacted, giving an arsonic acid. The solution was diluted with water to $200 \mathrm{ml}$, acidified with conc. $\mathrm{HCl}$ to $\mathrm{pH} 2$, and evaporated to dryness with a rotary evaporator. The residue was extracted twice with ethanol to eliminate most of the $\mathrm{NaCl}$ formed. The ethanolic solution was evaporated to dryness; the crude product was dissolved in water and passed through a column $(10 \times 2.5 \mathrm{~cm})$ of Dowex 50W X8 (acid form) and washed out with water. The $\mathrm{pH}$ was adjusted to 10.5 with $\mathrm{LiOH}$ and the solution evaporated to a small volume. The dilithium salt crystallized on addition of acetone, yield $23.0 \mathrm{~g}(57 \%)$. Electrophoresis showed a single spot. In proton $\mathrm{NMR}$ at $60 \mathrm{MHz}$ in ${ }^{2} \mathrm{H}_{2} \mathrm{O}$ it showed bands at $\delta 2.07$ $\left[2 \mathrm{H}, \mathrm{d}, 6 \mathrm{~Hz}, \mathrm{CH}-\mathrm{CH}_{2}-\mathrm{As}\right], 3.7\left[2 \mathrm{H}\right.$, broad, $\left.\mathrm{HO}-\mathrm{CH}_{2}-\mathrm{CH}\right]$ and $4.2[1 \mathrm{H}$, broad, $\mathrm{CH}_{2}-\mathrm{CH}(\mathrm{OH})-\mathrm{CH}_{2}$ ]. Elemental analysis: $\mathrm{C}, 17 \cdot 14,17 \cdot 05 \% ; \mathrm{H}$, $3.29,3.19 \% ; \mathrm{C}_{3} \mathrm{H}_{7} \mathrm{AsLi}_{2} \mathrm{O}_{5}$ requires $\mathrm{C}, 17.00 \% ; \mathrm{H}, 3.33 \%$.

2-Oxoethylarsonic acid (2-arsonoacetaldehyde). A sample of $10 \mathrm{ml}$ $50 \mathrm{~mm}$-dilithium 2,3-dihydroxypropylarsonate at its original $\mathrm{pH}(10 \cdot 5)$, and samples adjusted to $\mathrm{pH} 7.5$ and 3.5 with $\mathrm{HCl}$ were each treated with $0.13 \mathrm{~g}(0.61 \mathrm{mmol}) \mathrm{NaIO}_{4}$. After $10 \mathrm{~min}$, samples were taken for paper electrophoresis, which was carried out at $\mathbf{p H} 3 \cdot 5$. The arsonatepositive spot of relative mobility 0.14 compared to arsenate had been converted to one of mobility 0.26 ; characterization of this solution as one of arsonoacetaldehyde was indirect as follows, because all attempts to isolate it from solution as a salt led to its partial breakdown to arsenate. Addition before electrophoresis of an equal volume of $0.2 \mathrm{M}$ $\mathrm{NaBH}_{4}$ converted this spot to one of mobility $0 \cdot 16$, co-running with 2-hydroxyethylarsonic acid, confirming that the new spot was arsonacetaldehyde. This identification was further confirmed by treating a

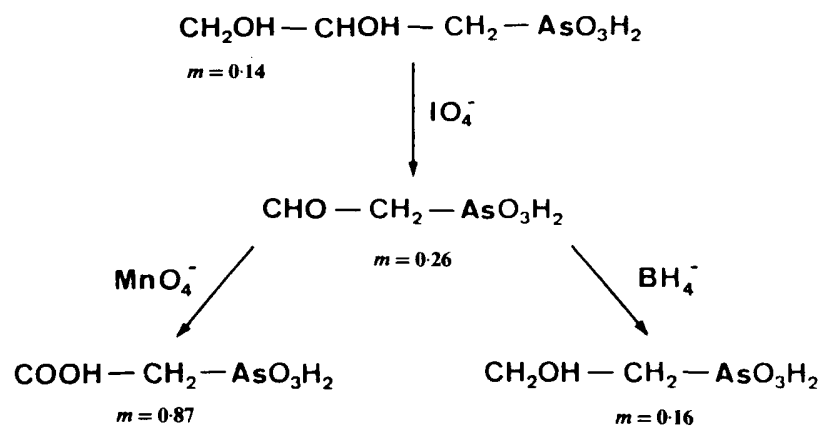

Fig. 1. Chemical formation of 2-oxoethylarsonic acid. $m$, electrophoretic mobilities of the arsonates relative to that of arsenate $(m=1)$.

solution of dilithium 2,3-dihydroxypropylarsonate at $\mathrm{pH} 10.5$ with $\mathrm{NaIO}_{4}$ as above, and oxidizing the aldehyde to the carboxylic acid as Isbell et al. (1969) had done with phosphonoacetaldehyde. Aqueous $5 \%$ $(\mathrm{w} / \mathrm{v}) \mathrm{KMnO}_{4}$ was added dropwise until its colour persisted. The solid $\mathrm{MnO}_{2}$ was filtered off and $5 \%(\mathrm{w} / \mathrm{v})$ aqueous $\mathrm{NaHSO}_{3}$ was added dropwise until the solution was colourless. Electrophoresis at $\mathrm{pH} 3.5$ showed conversion of the spot of relative mobility 0.26 into one of relative mobility 0.87 , co-running with arsonoacetate, and some formation of arsenate (see Fig. 1 below).

2-Aminoethylphosphonic acid. This was prepared by phosphonation of $N$-(2-bromoethyl)phthalimide with triethyl phosphite according to the method of Kosolapoff (1947). [1-14 C]AEP [29 mCi mmol ${ }^{-1}(1.07 \mathrm{GBq}$ $\left.\mathrm{mmol}^{-1}\right)$ ] was purchased from CEA, France.

Phosphonoacetaldehyde. This was prepared according to the method of Isbell et al. (1969).

Enzymes. 2-Aminoethylphosphonate:pyruvate aminotransferase (EC 2.6.1.37) and phosphonoacetaldehyde hydrolase (EC 3.11.1.1) were purified from cell-free extracts of $P$. aeruginosa grown in media containing AEP as sole nitrogen source for the aminotransferase (Dumora et al., 1983) or as both phosphorus and carbon source for the hydrolase (Dumora et al., 1989).

\section{Enzyme assays}

AEP-aminotransferase. This was assayed by incubating at $30^{\circ} \mathrm{C}$ a mixture containing AEA, APrA or AEP (1-20 mM), pyruvate (20 mM), pyridoxal 5'-phosphate $(100 \mu \mathrm{M})$ and the enzyme $(0.37 \mu \mathrm{M})$ in 2 -amino2-methylpropane-1,3-diol/HCl (Ammediol) buffer (100 mM), pH 8.5. The reaction was stopped by adding a $20 \%(\mathrm{w} / \mathrm{v})$ solution of sulphosalicylic acid $(0.125 \mathrm{ml}$ per $\mathrm{ml}$ of reaction mixture). The precipitate was removed by centrifugation. The amount of alanine formed was measured from a sample of the supernatant, diluted and adjusted to $\mathrm{pH} 2 \cdot 2$, with a high performance Amino Acid Analyzer (Beckman 6300 series). In order to quantify arsonoacetaldehyde produced concomitantly with alanine, the assay was carried out in a volatile buffer, triethylammonium bicarbonate $(100 \mathrm{mM}, \mathrm{pH} 8.5)$ in the presence of AEA (10 mM). After incubation, the reaction mixture was divided into two samples, A and B. Sample B was treated with borohydride. Reactions $A$ and $B$ were stopped by adding formic acid to $\mathrm{pH}$ 3.5. The reaction mixtures were then freeze-dried and the residues dissolved in water. An aliquot of each was electrophoresed at pH 3.5 to determine arsonoacetaldehyde in sample $A$ and 2-hydroxyethylarsonic acid in sample B. The amount of arsonoacetaldehyde was estimated by comparison with standards prepared from 2,3-dihydroxypropylarsonic acid as above.

Phosphonoacetaldehyde hydrolase. We could not determine directly whether this enzyme hydrolysed arsonoacetaldehyde $\left(\mathrm{CHO}-\mathrm{CH}_{2}-\right.$ $\mathrm{AsO}_{3} \mathrm{H}_{2}$ ), because this compound broke down when we tried to isolate 
it. We therefore estimated its rate of formation from the rate of alanine formation in the presence of aminotransferase and AEA $\left(\mathrm{NH}_{2}-\mathrm{CH}_{2-}\right.$ $\mathrm{CH}_{2}-\mathrm{AsO}_{3} \mathrm{H}_{2}$ ), and estimated its spontaneous rate of hydrolysis by determining the rate of acetaldehyde formation (using the coupled assay with alcohol dehydrogenase and NADH). Provided that formation was faster than hydrolysis, the breakdown of arsonoacetaldehyde accumulated in solution should be accelerated by phosphonatase if it is a substrate. To follow this process, both AEPaminotransferase $(0.9 \mu \mathrm{M})$ and yeast alcohol dehydrogenase ( $5 \mathrm{IU})$ were added to a solution containing AEA ( $10 \mathrm{~mm}$ ), pyruvate (10 mM), $\mathrm{MgCl}_{2}$ (10 mM) and NADH (0.16 mM) in Ammediol buffer (100 mM), pH 8.5, and the oxidation of NADH was measured as the decrease in absorbance at $340 \mathrm{~nm}$ and $25^{\circ} \mathrm{C}$ (Perkin Elmer $550 \mathrm{~S}$ ). This measurement was made both with and without addition of phosphonatase $(0.18 \mu \mathrm{M})$, to check whether acetaldehyde production increased when phosphonatase was added. To discover whether arsonoacetaldehyde inhibited phosphonatase, we incubated AEA $(20 \mathrm{mM})$ for $10 \mathrm{~min}$ with pyruvate (20 mM) and AEP-aminotransferase in Ammediol buffer (100 mM), pH 8.5, to allow arsonoacetaldehyde to accumulate (about $4 \mathrm{~mm}$ as judged by the production of alanine, and absence of acetaldehyde production). Phosphonatase and phosphonoacetaldehyde $(0.4 \mathrm{~mm})$ were then added. The reaction was monitored spectrophotometrically as above.

Uptake assays. P. aeruginosa was grown in a medium containing AEP (10 mM) as phosphorus source, glycerol $(30 \mathrm{mM}), \mathrm{NH}_{4} \mathrm{Cl}(10 \mathrm{mM})$, $\mathrm{MgCl}_{2}(2 \mathrm{mM}), \mathrm{K}_{2} \mathrm{SO}_{4}(4 \mathrm{mM})$ and $0.05 \%$ (w/v) yeast extract (Difco). Bacteria in the early stationary phase (about $2 \times 10^{9}$ cells ml $^{-1}$ ) were centrifuged, washed and suspended at a concentration of $1 \times 10^{9}$ cells $\mathrm{ml}^{-1}$ in a buffer solution of Tris/ $\mathrm{HCl}(50 \mathrm{mM}), \mathrm{KCl}(7.5 \mathrm{mM}), \mathrm{MgCl}_{2}$ (4 mM), pH 7.4, and glucose (10 mM). The cells were shaken for $30 \mathrm{~min}$ before addition of aminooxyacetate $(5 \mathrm{mM})$, which inactivated AEPaminotransferase. The uptake of $\left[1-{ }^{14} \mathrm{C}\right] \mathrm{AEP}$ was then measured over the range $1-50 \mu \mathrm{M}$. In order to investigate the inhibitory properties of AEA and APrA, fixed concentrations of AEA or APrA (50, 75 and $100 \mu \mathrm{M})$ were used against the different concentrations of labelled AEP. Samples were withdrawn at intervals and filtered rapidly on Millipore membrane filters $(0.45 \mu \mathrm{m})$ which were then washed with ice-cold Tris/ $\mathrm{HCl}$ buffer, dried and measured in a scintillation counter (Intertechnique SL 36), as described previously (Lacoste et al., 1976).

Growth studies. P. aeruginosa was able to grow at $30^{\circ} \mathrm{C}$ in the minimal culture medium containing HEPES $(50 \mathrm{mM}), \mathrm{pH} 7.5$, potassium phosphate (12 mM), succinic acid (30 mM), $\mathrm{NH}_{4} \mathrm{Cl}(10 \mathrm{mM}), \mathrm{MgCl}_{2}$ ( $2 \mathrm{mM}), \mathrm{K}_{2} \mathrm{SO}_{4}(4 \mathrm{mM})$ adjusted to $\mathrm{pH} 7.3$ with $\mathrm{KOH}$ solution. This minimal medium, in which $\mathrm{NH}_{4} \mathrm{Cl}$ can be replaced by another nitrogen source, was used for the following studies in which growth was recorded on a Bonet-Maury biophotometer at $650 \mathrm{~nm}$. (1) AEA as nitrogen source: AEA replacing $\mathrm{NH}_{4} \mathrm{Cl}$ in the above medium. (2) AEA as growth inhibitor: AEA was added to minimal medium containing AEP, or alanine, or $\mathrm{NH}_{4} \mathrm{Cl}$, as nitrogen source. Comparatively, APrA was added to minimal medium containing AEP, or 4-aminobutyric acid, or $\mathrm{HN}_{4} \mathrm{Cl}$, as nitrogen source.

Toluene treatment of $P$. aeruginosa cells grown on different nitrogen sources for the measurement of AEA-aminotransferase activities. Bacteria were grown in minimal media containing AEP, AEA, $\beta$-alanine or $\mathrm{NH}_{4} \mathrm{Cl}$ as sole nitrogen source, harvested in the stationary phase $(15 \mathrm{~h}$ for AEP, $\beta$-Ala, $\mathrm{NH}_{4} \mathrm{Cl} ; 55 \mathrm{~h}$ for AEA) and washed. From the pellets, toluene-treated bacteria were prepared as described by Payne (1973). For measurement of aminotransferase activities, $0.3 \mathrm{ml}$ of a suspension of toluene-treated cells was added to $1 \mathrm{ml}$ of reaction mixture (see Enzyme assays) containing either AEA, AEP or $\beta$-alanine as amino group donor. The reactions were carried out at $30^{\circ} \mathrm{C}$ for $2 \mathrm{~h}$, and stopped by heating for $5 \mathrm{~min}$ at $90^{\circ} \mathrm{C}$. After centrifugation, the alanine present in the supernatant was quantified by HPLC.

\section{Results}

Interaction of $A E A$ with the enzymes of $A E P$ catabolism

AEA is a substrate for AEP-aminotransferase; the alanine produced was readily determined by HPLC. To show that the reaction was exactly analogous to that with $\mathrm{AEP}$, as follows

$$
\mathrm{NH}_{2}-\mathrm{CH}_{2}-\mathrm{CH}_{2}-\mathrm{AsO}_{3} \mathrm{H}_{2}+\mathrm{CH}_{3}-\mathrm{CO}-\mathrm{COOH}
$$

we had to show that arsonoacetaldehyde was produced in amounts stoichiometric with the alanine. The products formed in our assay were analysed (i) by HPLC to quantify alanine, and (ii) by electrophoresis to detect and estimate arsonoacetaldehyde. Electrophoresis of sample A (freeze-dried after acidification) showed an arsonatepositive spot co-running with arsonoacetaldehyde obtained by treating 2,3-dihydroxypropylarsonic acid with sodium periodate; similarly sample B (treated with borohydride), showed an arsonate-positive spot corunning with 2-hydroxyethylarsonic acid (see Fig. 1).

In sample $\mathrm{A}$, the quantity of alanine and arsonoacetaldehyde generated from 2-aminoethylarsonate was found to be $1.60( \pm 0.01) \mathrm{mM}$ and $1.40( \pm 0.15) \mathrm{mM}$, respectively. These values give a clear indication of the stoichiometry of the transamination reaction.

The kinetic constants of AEP-aminotransferase for AEA were evaluated using Lineweaver-Burk plots; the values of $4 \mathrm{mM}$ for the $K_{\mathrm{m}}$ and of $0.5-0.6 \mathrm{mM} \mathrm{min}^{-1}$ for $V$ show that the enzyme has the same affinity for the arsonic compound as for its natural substrate AEP $\left(K_{m}\right.$ 3.85 mM) (Dumora et al., 1983). APrA, like 3-aminopropylphosphonic acid (APrP) (Cassaigne et al., 1976), was neither a substrate nor an inhibitor for AEPaminotransferase.

The assays for phosphonoacetaldehyde hydrolase were performed by following the formation of acetaldehyde when AEA was incubated with AEP-aminotransferase alone, or with both AEP-aminotransferase and phosphonatase. In the sole presence of AEP-aminotransferase, which released equimolar amounts of alanine and arsonoacetaldehyde, the spontaneous hydrolysis of the latter compound was slow: the formation of acetaldehyde, followed for $20 \mathrm{~min}$, was only $1 \mu \mathrm{M} \mathrm{min}{ }^{-1}$ whereas the formation of alanine was found to be $400 \mu \mathrm{M} \mathrm{min}^{-1}$. In the presence of both aminotransferase and phosphonatase, the reaction rates were unchanged, showing that arsonoacetaldehyde, which was relatively stable under our experimental conditions, was not a substrate for the phosphonatase.

Furthermore, to determine whether arsonoacetalde- 


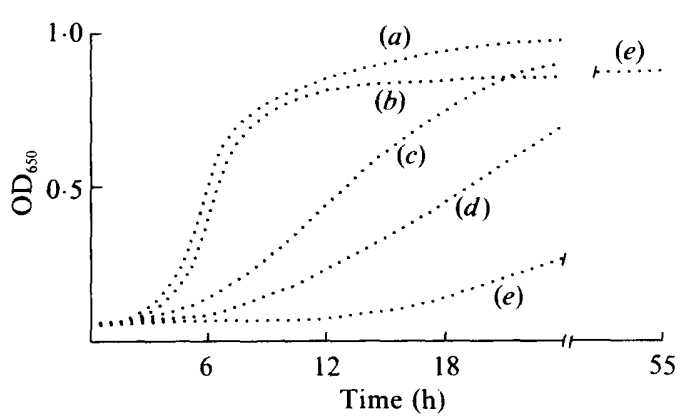

Fig. 2

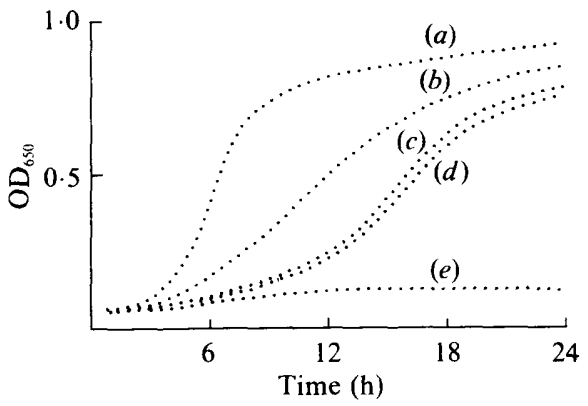

Fig. 3

Fig. 2. Effect of AEP or AEA alone and in combination on growth of P. aeruginosa. The arsonic and phosphonic compounds were added as nitrogen source, in medium containing: $10 \mathrm{mM}-\mathrm{K}_{2} \mathrm{HPO}_{4}, 30 \mathrm{~mm}$-succinic acid, $2 \mathrm{mM}-\mathrm{MgCl}_{2}, 4 \mathrm{mM}-\mathrm{K}_{2} \mathrm{SO}_{4}, 50 \mathrm{mM} \mathrm{HEPES}$ buffer (pH 7.5), adjusted to pH 7.3 with $\mathrm{KOH}$ solution. Curve (a) 5 or $10 \mathrm{mM}$-AEP; (b) $2.5 \mathrm{mM}$-AEP; (c) 5 mM-AEP + 5 mM-AEA $([\mathrm{AEA}] /[\mathrm{AEP}]=1) ;(d) 2.5 \mathrm{mM}-\mathrm{AEP}+7.5 \mathrm{mM}-\mathrm{AEA}([\mathrm{AEA}] /[\mathrm{AEP}]=3) ;(e) 10 \mathrm{mM}-\mathrm{AEA}$.

Fig. 3. Effect of AEA, APrA and APrP on growth of $P$. aeruginosa cultivated on AEP as nitrogen source. The arsonic and phosphonic compounds were added to the medium described in Fig. 2 at the following concentrations. Curve $(a) 5$ mM-AEP; $(b) 5$ mM-AEP +5 mMAEA; (c) 5 mM-AEP + 5 mM-APrA ; (d) 5 mM-AEP + 5 mM-APrP; (e) $2.5 \mathrm{~mm}$-AEP + 7.5 mM-APrA or 2.5 mM-AEP + 7.5 mM-APrP.

hyde is an inhibitor of the phosphonatase, the reaction was started by phosphonoacetaldehyde $(0.4 \mathrm{mM})$ in the presence of preformed arsonoacetaldehyde (3-4 mM) as described in Methods. This compound did not affect the production of acetaldehyde, and hence does not inhibit phosphonoacetaldehyde hydrolase.

\section{Uptake assays}

We have previously characterized a high-affinity inducible transport system for AEP in $P$. aeruginosa $\left(K_{\mathrm{m}} 6 \mu \mathrm{M}\right)$ (Lacoste et al., 1976). The inhibition of the intracellular incorporation of $\left[1{ }^{14} \mathrm{C}\right] \mathrm{AEP}$ by AEA and APrA was found to be competitive (Lineweaver-Burk plots). The same $K_{\mathrm{i}}$ value of $18 \mu \mathrm{M}$ was calculated for both AEA and APrA.

\section{Growth studies}

Fig. 2 shows a slow utilization of AEA as a nitrogen source by $P$. aeruginosa. After a long lag phase, growth was almost linear for $55 \mathrm{~h}$, whereas AEP was an efficient nitrogen source comparable to L-alanine or $\mathrm{NH}_{4} \mathrm{Cl}$. Moreover, AEA added to the AEP medium was inhibitory. The level of inhibition varied as the ratio of [AEA]/[AEP] increased. No inhibition was observed in a mixture of AEA and alanine (or $\mathrm{NH}_{4} \mathrm{Cl}$ ).

Unlike AEA, APrA was not a nitrogen source for $P$. aeruginosa. However, it acted as a better growth inhibitor than AEA when added to the AEP medium; it is noteworthy that the inhibition was similar to that found with APrP (Fig. 3). No inhibition was observed in a mixture of APrA and 4-aminobutyric acid (or $\mathrm{NH}_{4} \mathrm{Cl}$ ).

\section{Catabolism of $A E A$ by $P$. aeruginosa}

Since $P$. aeruginosa is able to utilize AEA as sole nitrogen source, we sought to determine whether its deamination proceeds via (i) a specific aminotransferase, (ii) the AEPaminotransferase as demonstrated in vitro, (iii) another pathway, such as the non-specific $\omega$-amino acid:pyruvate aminotransferase (Yonaha et al., 1976) induced by $\beta$-alanine, the carboxylic analogue of AEP and AEA.

To test this point, $P$. aeruginos $a$ was grown in different minimal media containing AEA, AEP, $\beta$-Ala or $\mathrm{NH}_{4} \mathrm{Cl}$ as sole nitrogen source. The aminotransferase activities were examined in toluene-permeabilized cells. Only the cells grown on AEP or AEA showed the ability to degrade these two compounds (Table 1); both were degraded equally well but the aminotransferase activity of cells grown on AEP was greater.

These results together with the in vitro assays provide evidence that (i) AEA was catabolized in vivo by the AEP aminotransferase, and (ii) AEA was able to induce this enzyme but less effectively than AEP did (the yield was about 3-fold lower at the end of growth).

Table 1. Aminotransferase activities of cells of $P$. aeruginosa grown with various nitrogen sources

The enzyme assay system contained $20 \mu \mathrm{mol}$ amino acid, $20 \mu \mathrm{mol}$ pyruvate, $100 \mu \mathrm{mol}$ Ammediol buffer $\mathrm{pH} 8.5,0.3 \mathrm{ml}$ toluenepermeabilized cells (suspension $\mathrm{OD}_{650}=1.5$ ) in a final volume of $1 \mathrm{ml}$. Incubation was for $2 \mathrm{~h}$ at $30^{\circ} \mathrm{C}$. Values are the means of triplicate assays \pm standard error of the mean.

\begin{tabular}{lcccc}
\hline \hline \multirow{2}{*}{$\begin{array}{c}\text { Nitrogen } \\
\text { source } \\
(10 \mathrm{mM})\end{array}$} & $\begin{array}{c}\text { Growth } \\
\text { time } \\
(\mathrm{h})\end{array}$ & \multicolumn{3}{c}{$\begin{array}{c}\text { Alanine formation }(\mu \mathrm{mol}) \text { by } \\
\text { transamination reaction using as } \\
\text { amino donor: }\end{array}$} \\
\cline { 3 - 5 } & AEA & AEP & $\beta$-Alanine \\
\hline AEA & 55 & $2 \cdot 4 \pm 0 \cdot 2$ & $2 \cdot 6 \pm 0 \cdot 2$ & 0 \\
AEP & 15 & $7 \cdot 6 \pm 0 \cdot 6$ & $8 \cdot 0 \pm 0 \cdot 7$ & 0 \\
$\beta$-Alanine & 15 & 0 & 0 & $9 \cdot 2 \pm 0.8$ \\
\hline \hline
\end{tabular}




\section{Discussion}

We have shown that the AEP-aminotransferase has almost the same kinetic constants for $\mathrm{NH}_{2}-\mathrm{CH}_{2}-\mathrm{CH}_{2}-$ $\mathrm{AsO}_{3} \mathrm{H}_{2}$ (AEA) as for its natural substrate, $\mathrm{NH}_{2}-\mathrm{CH}_{2}-$ $\mathrm{CH}_{2}-\mathrm{PO}_{3} \mathrm{H}_{2}$, (AEP). Visedo-Gonzalez \& Dixon (1989) similarly found that AEA can replace AEP as a substrate for ethanolamine-phosphate cytidylyltransferase; AEP had previously been shown to replace the natural substrate ethanolamine phosphate, $\mathrm{NH}_{2}-\mathrm{CH}_{2}-\mathrm{CH}_{2}-\mathrm{O}$ $\mathrm{PO}_{3} \mathrm{H}_{2}$ (Tamari et al., 1973). Whereas the aminotransferase is specific for the 2-aminoethyl compounds, and has no action on the corresponding 3-aminopropyl compounds, the uptake system appears to accommodate both arsonates. Both show the same $K_{\mathrm{i}}(18 \mu \mathrm{M})$ in inhibiting the uptake of labelled aminoethylphosphonate by the cells. This is similar to the values $(12.5 \mu \mathrm{M}$ and $12 \mu \mathrm{M})$ for 3-aminopropylphosphonic acid and ethanolamine phosphate respectively (Lacoste $e t$ al., 1976), in inhibiting the uptake of AEP.

Although AEA, unlike APrA, can serve as a nitrogen source, $P$. aeruginosa grows only slowly in its presence. This could be due to limiting transport, or to low induction of the enzyme that catabolizes it, or because the product of its deamination is toxic.

The fact that AEA inhibits the growth of $P$. aeruginosa when AEP is present as the only other nitrogen source, but not when alanine or $\mathrm{NH}_{4} \mathrm{Cl}$ is present, may be due to the fact that AEA competes with AEP for uptake. APrA and APrP are better growth inhibitors, although no better in competing with AEP for uptake. This may be connected with the fact that they are not broken down by the transaminase.

Moreover, the ability of AEA to induce AEPaminotransferase shows that it must bind to the genomic site that regulates expression of this enzyme. However, the lower efficacy of AEA in inducing the aminotransferase could be due to the sensitivity of the regulator system either to the larger size of the $-\mathrm{AsO}_{3} \mathrm{H}_{2}$ group or to a lower intracellular concentration of AEA controlled by the transport system.

The catabolism of AEA by $P$. aeruginosa generates alanine, which provides the cell with nitrogen, and arsonoacetaldehyde, which slowly hydrolyses spontaneously to arsenate and acetaldehyde. The slow growth observed is probably not due to this arsenate, both because the rate of release in vitro is slow and because the strain of Pseudomonas used is resistant to arsenate (its growth rate was not changed by $8 \mathrm{~mm}$-arsenate in the initial minimal medium). It might be due to the slowness with which the permease and aminotrasferase were induced, and hence to poor supply of alanine by transamination.

We thank Mrs F. Denois for the synthesis of 2-aminoethylphosphonic acid, Mr M. J. Sparkes for skilled assistance and helpful discussion, and the Karim Rida Said Foundation, the Cambridge Overseas Trust, and the UK Overseas Research Students Award Scheme, for financial support of B.R.S.A.

\section{References}

Ambler, R. P. (1963). The amino acid sequence of Pseudomonas cytochrome C-551. Biochemical Journal 89, 349-378.

Cassaigne, A., Lacoste, A. M. \& Neuzil, E. (1976). Recherches sur le catabolisme des acides phosphoniques: biodégradation de la liaison C-P par Pseudomonas aeruginosa. Comptes Rendus Académie des Sciences Paris 282, 1637-1639.

Dixon, H. B. F. \& SPARKes, M. J. (1974). Phosphonomethyl analogues of phosphate ester glycolytic intermediates. Biochemical Journal 141, 715-719.

Dumora, C., Lacoste, A. M. \& Cassaigne, A. (1983). Purification and properties of 2-aminoethylphosphonate: pyruvate aminotransferase from Pseudomonas aeruginosa. European Journal of Biochemistry 133, 119-125.

Dumora, C., lacoste, A. M. \& Cassaigne, A. (1989). Phosphonoacetaldehyde hydrolase from Pseudomonas aeruginosa: purification, properties and comparison with Bacillus cereus enzyme. Biochimica et Biophysica Acta 997, 193-198.

Geoghegan, K. F. \& Dixon, H. B. F. (1989). Synthesis of 2aminoethylarsonic acid. A new synthesis of primary amines. Biochemical Journal 260, 295-297.

GougH, G. A. C. \& KING, H. (1928). Trypanocidal action and chemical constitution. VIII. Derivatives of $\beta$-aminoethyl- and $\gamma$ aminopropylarsinic acids. Journal of the Chemical Society 2426-2447.

IsBell, A. F., ENGLeRT, L. F. \& RosenBerG, H. (1969). Phosphonoacetaldehyde. Journal of Organic Chemistry 34, 755-756.

KosolapofF, G. M. (1947). The synthesis of amino-substituted phosphonic acids. Journal of the American Chemical Society 69, 2112 2113.

lacoste, A. M., Cassaigne, A., Tamari, M. \& Neuzil, E. (1976). Transport de l'acide amino-2-éthylphosphonique chez Pseudomonas aeruginosa. Biochimie 58, 703-712.

Neuzil, E. \& Cassaigne, A. (1980). Composés naturels à liaison P-C et phosphonates d'intérêt biologique. Exposés Annuels de Biochimie Médicale 165-210.

PAYNe, J. W. (1973). Peptide utilization in Escherichia coli: studies with peptides containing $\beta$-alanyl residues. Biochimica et Biophysica Acta 298, 469-478.

Tamari, M., Maget-Dana, R., Marmouyet, J. \& Douste-Blazy, L. (1973). CMP-aminoéthylphosphonate : intermédiaire de la biosynthèse des phosphonolipides dans le foie de rat. Biochimie 55, 1311-1312.

Tsivgoulis, G. M., Sotiropoulos, D. N. \& IoAnNou, P. V. (1991). 1,2Dihydroxypropyl-3-arsonic acid: a key intermediate for arsonolipids. Phosphorus, Sulfur, and Silicon 57, 189-193.

Visedo-Gonzalez, E. \& Dixon, H. B. F. (1989). 2-Aminoethylarsonic acid as an analogue of ethanolamine phosphate. Endowment of ethanolamine-phosphate cytidylyltransferase with CTP pyrophosphatase activity. Biochemical Journal 260, 299-301.

WaDE, H. E. \& Morgan, D. M. (1953). Detection of phosphate esters on paper chromatograms. Nature, London 171, 529-530.

Yonaha, K., Toyama, S., Yasuda, M. \& Soda, K. (1976). Purification and crystallization of bacterial $\omega$-aminoacid-pyruvate aminotransferase. FEBS Letters 71, 21-24. 